OPEN ACCESS

Edited by:

Neil Rosser,

Harvard University, United States

Reviewed by:

Jessie Santos,

State University of Campinas, Brazil

Rita Gomes Rocha,

Centro de Investigacao em

Biodiversidade e Recursos Geneticos (CIBIO-InBIO), Portugal

*Correspondence:

Rafael M. Rabelo

rmrabelo@gmail.com

Specialty section:

This article was submitted to Biogeography and Macroecology,

a section of the journal

Frontiers in Ecology and Evolution

Received: 10 April 2021 Accepted: 10 August 2021

Published: 30 August 2021

Citation:

Rabelo RM, Pereira GCN,

Valsecchi J and Magnusson WE (2021) The Role of River Flooding as an Environmental Filter for Amazonian

Butterfly Assemblages.

Front. Ecol. Evol. 9:693178. doi: 10.3389/fevo.2021.693178

\section{The Role of River Flooding as an Environmental Filter for Amazonian Butterfly Assemblages}

\author{
Rafael M. Rabelo ${ }^{1,2 *}$, Geanne C. N. Pereira ${ }^{2,3}$, João Valsecchi ${ }^{2,4}$ and \\ William E. Magnusson ${ }^{1,5}$
}

${ }^{1}$ Programa de Pós-Graduação em Ecologia, National Institute of Amazonian Research (INPA), Manaus, Brazil, ${ }^{2}$ Grupo de Pesquisa em Ecologia de Vertebrados Terrestres, Instituto de Desenvolvimento Sustentável Mamirauá, Tefé, Brazil, ${ }^{3}$ Programa de Pós-Graduação em Ecologia e Conservação da Biodiversidade, Universidade Estadual de Santa Cruz, Ilhéus, Brazil, ${ }^{4}$ Rede de Pesquisa em Diversidade, Conservação e Uso da Fauna da Amazônia (REDEFAUNA), Manaus, Brazil,

${ }^{5}$ Coordenação de Pesquisa em Biodiversidade, National Institute of Amazonian Research (INPA), Manaus, Brazil

Amazonian flooded (várzea) and upland (terra firme) forests harbor distinct assemblages of most taxonomic groups. These differences are mainly attributed to flooding, which may affect directly or indirectly the persistence of species. Here, we compare the abundance, richness and composition of butterfly assemblages in várzea and terra firme forests, and evaluate whether environmental gradients between and within these forest types can be used to predict patterns of assemblage structure. We found that both total abundance and number of species per plot are higher in várzea than in terra firme forests. Várzea assemblages had a higher dominance of abundant species than terra firme assemblages, in which butterfly abundances were more equitable. Rarefied species richness for várzea and terra firme forests was similar. There was a strong turnover in species composition from várzea to terra firme forests associated with environmental change between these forest types, but with little evidence for an effect of the environmental gradients within forest types. Despite a smaller total area in the Amazon basin, less defined vegetation strata and the shorter existence over geological time of floodplain forests, Nymphalid-butterfly assemblages were not more speciespoor in várzea forests than in unflooded forests. We highlight the role of flooding as a primary environmental filter in Amazonian floodplain forests, which strongly determines the composition of butterfly assemblages.

Keywords: Amazonian floodplains, Lepidoptera, rarefaction, species composition, species density, species richness, terra firme, várzea

\section{INTRODUCTION}

The number and composition of species at a given site is always a small subset of the regional species pool because environmental and biotic factors act together or separately to filter species from the regional pool and select the species composition at local scales (Hubbell, 2005). Vegetation type is the biotic feature most often used to represent the spatial distribution of forest-dwelling species, and several forest types occur in Amazonian landscapes.

Upland (terra firme) forests account for approximately 83\% of the Amazon basin (Melack and Hess, 2010) and are located above the maximum seasonal flood levels of rivers, lakes, and large 
streams. Várzea forests are seasonally flooded by nutrient-rich white-water rivers for 6-8 months, and water-level fluctuations can reach up to $14 \mathrm{~m}$ (Junk et al., 2012). Várzea forests cover $~ 7 \%$ of the Amazon basin (Melack and Hess, 2010).

Várzea and terra firme forests harbor distinct assemblages of trees (Wittmann et al., 2004), terrestrial mammals (Alvarenga et al., 2018), bats (Bobrowiec et al., 2014), birds (Beja et al., 2010), litter frogs (Gascon, 1996), and ants (Pringle et al., 2019). Poorer assemblages of several animal groups have been consistently documented in várzea forests (Haugaasen and Peres, 2005b; Bobrowiec et al., 2014; Alvarenga et al., 2018; Pringle et al., 2019), suggesting that seasonal inundation explains the lower number of terrestrial and understorey species. In contrast, terra firme should have higher species richness than várzea forest because it offers more niches associated with the understorey vegetation (Pereira et al., 2009).

It is expected that terra firme forests should contain more speciose assemblages of those species groups that can persist in both várzea and terra firme forests. Terra firme forests should have more species than flooded forests since they cover a much larger area (MacArthur and Wilson, 1967), have more stratified vegetation (MacArthur and MacArthur, 1961), and have existed over a longer period of geological time (Ruokolainen et al., 2018). With more species, it is also expected that species abundances in terra firme assemblages would be more equitable (MacArthur, 1969). On the other hand, várzea forests tend to have higher species abundance/biomass (Haugaasen and Peres, 2005b; Pereira et al., 2009; Pringle et al., 2019) due to the high forest primary productivity, as the white-water seasonal flooding fertilizes várzea soils (Haugaasen and Peres, 2006). Higher abundance/biomass in várzea forests due to the higher primary productivity has been documented mainly for mammals, but also for arboreal ant species (Pringle et al., 2019).

Butterflies are strongly associated with specific habitats at all life stages (Freitas et al., 2006) and are relatively sedentary in the larval stage, but are highly vagile in the adult phase and can have seasonal adaptations (phenological or migratory) to environmental changes (Diamond et al., 2011; Chowdhury et al., 2021). Vegetation gradients represent changes in the availability of food resources and physical conditions of the environment, which directly affect the spatial distribution of Amazonian fruitfeeding butterflies (Ribeiro and Freitas, 2012; Graça et al., 2015, 2017a). Therefore, environmental changes, such as seasonal flooding, can also filter species from the regional pool, affecting local species richness and composition.

This study compares the butterfly assemblages of várzea and terra firme forests in central Amazonia. Specifically, we aim (i) to test whether the density, richness and composition of butterflies differs between várzea and terra firme forests; (ii) to compare the species-abundance distribution between the two forest types; and (iii) to evaluate how the assemblage structure is associated with environmental (topography and vegetation) gradients between and within forest types. We expected to find a higher butterfly density in várzea forests because they have higher forest primary productivity, which represents higher availability of food resources than in terra firme forests. On the other hand, given that terra firme forests represent a more stable environment and cover a larger area, we expected higher species richness in this forest type. We also predicted that the species-abundance distribution would be evener in terra firme forests due to its higher species richness, in comparison with várzea forests, in which we should find a higher dominance of abundant species. We also expected to find strong turnover in species composition associated with forest type and environmental gradients.

\section{MATERIALS AND METHODS}

\section{Study Area}

Sampling was undertaken in three Amazonian protected areas: Amanã Sustainable Development Reserve, Mamirauá Sustainable Development Reserve and Baixo Juruá Extractive Reserve, in the Middle-Solimões (upper Amazon) River region, in Central Amazonia (Figure 1). These protected areas contain floodplains covered largely by várzea forests, which are adjacent to terra firme forests (ICMBio, 2009; IDSM, 2010). During the highwater season, várzea forests are flooded by nutrient-rich whitewater rivers, with an average annual water-level range of 15 $\mathrm{m}$. Highest river levels occur around May-June and minima in October-November (ICMBio, 2009; IDSM, 2010). Mean annual temperature and precipitation were around $26-31^{\circ} \mathrm{C}$ and $2,200-$ $2,400 \mathrm{~mm}$, respectively, with mean precipitation around 60$80 \mathrm{~mm}$ during the dry season (ICMBio, 2009;IDSM, 2010).

\section{Sampling Design and Data Collection}

Sampling was done in 15 plots located in várzea and 21 in terra firme forests (Figure 1) during the low-water season in all study areas (RDS Amanã in November-December 2017, RESEX Baixo Juruá in July 2018, RDS Mamirauá in August 2019). We were not able to conduct sampling in both high- and low-water seasons due to logistical constraints. The sampling design followed the RAPELD method as part of a long-term ecological project that aims to compare the distributions of multiple taxa (Magnusson et al., 2005). Plots (sample units) consisted of a 250-m long center line, separated by at least $500 \mathrm{~m}$ from one another (Figure 1).

Butterfly surveys were conducted via active and passive sampling. We placed six equally spaced baited butterfly traps along the center line of each plot. Traps were hung from tree branches in the forest understorey ( $\sim 1.5 \mathrm{~m}$ high). We baited the traps with a mixture of sugar-cane juice and bananas fermented for $48 \mathrm{~h}$ (Freitas et al., 2014) and visited them every $24 \mathrm{~h}$ to check for captures and replace the bait. We left the traps active for six consecutive days in each plot. This sampling effort is based on Graça et al. (2017b), who suggested that it is sufficient to identify ecological responses of understorey fruit-feeding butterfly assemblages.

We also used insect nets to sample low-flying Haeterini species and other Nymphalid species that usually are not caught with baited traps. On each visit to the plots, two researchers with standard $37-\mathrm{cm}$ diameter insect nets actively searched for butterflies during $30 \mathrm{~min}$. All captured individuals were collected for posterior species identification. Butterflies were identified to species level using on line resources ${ }^{1}$ and the taxonomic literature. All identifications were verified by an

${ }^{1}$ www.butterfliesofamerica.com 

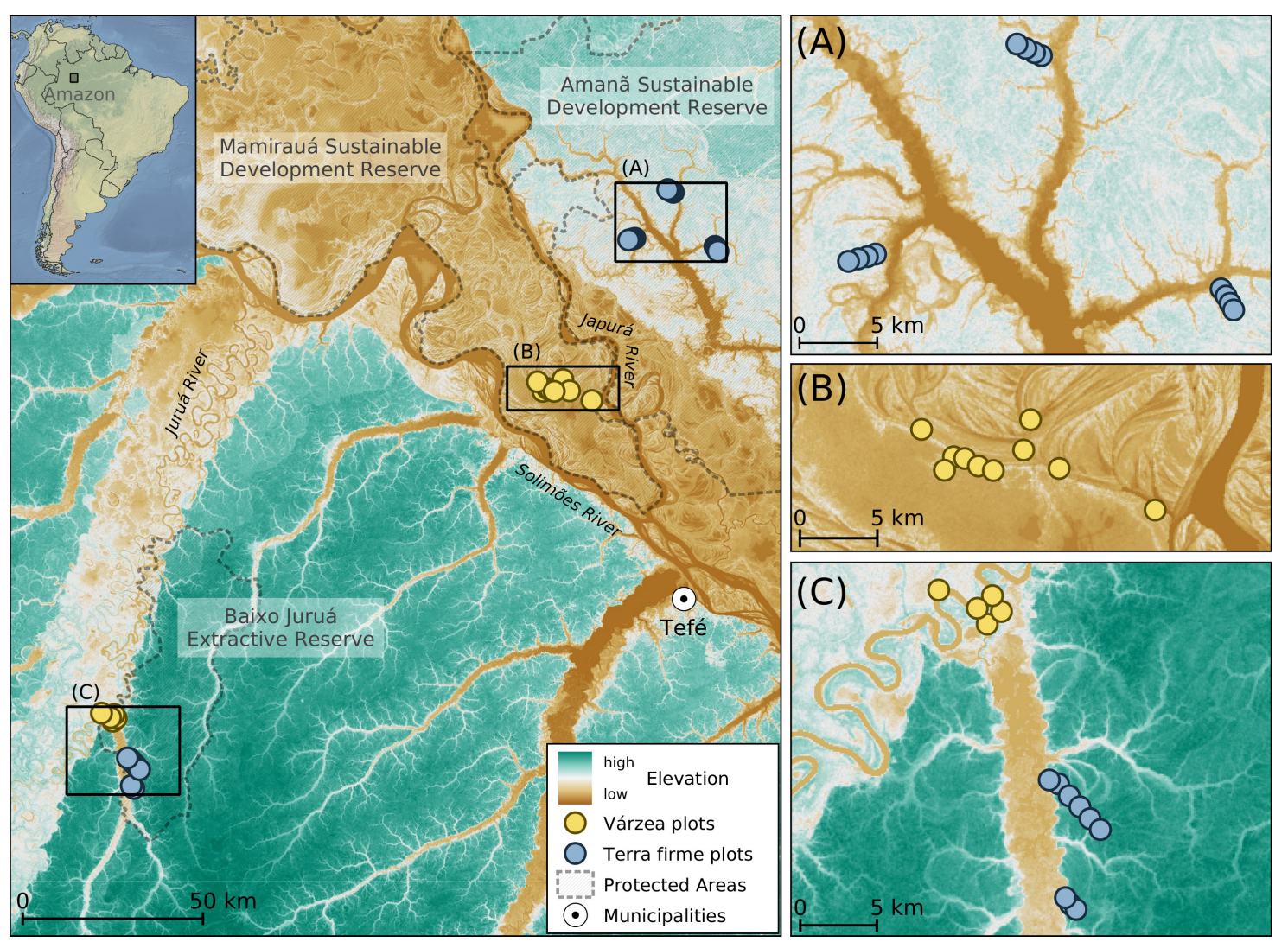

FIGURE 1 | Distribution of sample plots in várzea and terra firme forests. Maps show the distribution of sampling plots overlapped with an elevation Radar image from the Shuttle Radar Topography Mission (SRTM). Black rectangles in the left map are enlarged in right panels (A-C).

expert taxonomist (T. Zacca). To avoid taxonomic uncertainty, especially because our study area is located in a region with many biodiversity-knowledge shortfalls (Hortal et al., 2015), where butterflies have been poorly inventoried (Santos et al., 2008), some specimens could not be identified to species level, so we identified them as morphospecies. Although not ideal, the use of morphospecies is a way to deal with taxonomic constraints in ecological studies, and they appear to provide a reliable alternative to taxonomic species in Lepidoptera (91\% of matching accuracy; Derraik et al., 2002). All specimens were deposited in the Entomological Collection of the Mamirauá Institute for Sustainable Development, Tefé, Brazil.

We gathered topographic and vegetation data to characterize the environmental gradients across várzea and terra firme plots. Topography data consisted of elevation, height above nearest drainage (HAND) and flooded terrain during the high-water season, which were extracted from an image provided by the Synthetic Aperture Radar of the Japonese Earth Resources Satellite-JERS-1 SAR. ${ }^{2}$ In the Amazon, JERS-1/SAR images indicate flooded-forest areas by brighter pixels, closed-canopy forests by median brightness, and open water as darker pixels. Vegetation data consisted of estimates of \% of tree cover, canopy height, enhanced vegetation index (EVI) and

${ }^{2}$ http://earth.esa.int net primary productivity (NPP) obtained from GIS databases (Supplementary Table 1). EVI is a vegetation index that is correlated with forest primary productivity and vegetation structure (Huete et al., 2002).

\section{Data Analysis}

We report two indices of butterfly diversity: species density and rarefied species richness. These measures emphasize different components of diversity while controlling for potential sampling bias. Species density records the number of species per sample unit. The rarefied species richness (hereafter "species richness"), is used to estimate expected species richness at constant total abundance, since increased number of species is expected as a random consequence of larger pools of individuals (Gotelli and Colwell, 2001).

We compared the total abundance and observed number of species per plot between várzea and terra firme forests with Kruskal-Wallis tests, as the data had non-normal distributions. We used rarefaction and extrapolation of standardized number of species to compare species richness in both forest types. We standardized the number of species by both number of sampled individuals and sampling coverage, following the recommendations of Chao et al. (2014). Rarefaction and extrapolation were based on sampling coverage, in 
addition to sample size, because standardizing samples by number of individuals usually underestimates species richness of assemblages with more species (Chao and Jost, 2012). We also used Kolmogorov-Smirnov tests to compare the species-abundance curves from the two forest types and sampling methods.

We built a species by site matrix, recording each species abundance (columns) per plot (rows). Then we standardized the abundances by dividing the number in each matrix cell by the total abundance in the matrix row (plots) to reduce the discrepancy between sites with different number of samples. We summarized butterfly species composition by non-metric multidimensional scaling (NMDS) ordination with two axes, based on the Bray-Curtis dissimilarity index. Then, we used a permutational multivariate analysis of variance (PERMANOVA) to evaluate whether the species composition differed between the two forest types. We reran this analysis excluding singletons and doubletons, since rare species can introduce variation in the assemblage structure that may not be related to habitat (Beja et al., 2010). We used a principal component analysis (PCA) to summarize the environmental data from plots and used the first axis of this ordination to represent the environmental gradient across plots. We then used an NMDS with one dimension to reduce the dimensionality of data into only one axis, using the scores derived from this ordination to represent the butterfly species composition in each plot. We used this second NMDS ordination with only one axis because NMDS is not an eigenvalue technique, and it does not maximize the variability associated with individual axes of the ordination, so the axes are not orthogonal to each other (Legendre and Legendre, 1998). We then used the single NMDS axis, which represented the ordering of sites according to their similarity in species composition (i.e., the assemblage structure), as the response variable in a generalized linear model (GLM) to evaluate whether it changes with environmental gradients (PCA 1) and across forest types (várzea or terra firme). We included latitude and longitude as predictors in the GLM to account for potential effect of spatial gradients and tested for spatial autocorrelation in model residuals with Moran's I. All analyses were undertaken in the vegan 2.4-4 (Oksanen et al., 2013) and iNEXT (Hsieh et al., 2016) packages of the R 3.4.4 statistical software (R Development Core Team, 2018).

\section{RESULTS}

We captured 913 individuals belonging to 99 butterfly species (Supplementary Table 2), in a total sampling effort of 1,296 trap*days (540 in várzea and 756 in terra firme) and $144 \mathrm{~h}$ (60 in várzea and 84 in terra firme). The most frequently captured species in várzea forests was Magneuptychia aff. ocnus, whereas Bia actorion was the most frequently captured species in terra firme (Supplementary Figure 1). Singletons and doubletons were represented by 36 species ( $~ 51 \%)$ in várzea forests and 23 species $(\sim 51 \%)$ in terra firme. The number of species exclusive to várzea and to terra firme was 56 and 29, respectively, and 16 species were shared between the two forest types.
The median number of butterfly individuals counted per plot in várzea forests was 28 (first quartile (Q1) and third quartile $(\mathrm{Q} 3)=24$ and 58, respectively), and it was significantly higher than the number of individuals counted in terra firme plots $(\mathrm{Q} 1=5 ;$ median = 9; $\mathrm{Q} 3=10 ;$ Kruskal-Wallis, $H=22.64$, $p<0.001$; Figure 2A). The abundance distribution of species also differed between the two forest types (Kolmogorov-Smirnov, baited traps: $D=0.85, p<0.001$; insect nets: $D=0.71$, $p<0.001$; both methods: $D=0.66, p<0.001$; Figure 2C and Supplementary Figure 2). The várzea assemblage had higher dominance of abundant species [three (4\%) species made up $50 \%$ of all individuals, Supplementary Figure 1] than the terra firme assemblage, which had an evener distribution of species abundance [eight (18\%) species accounted for $50 \%$ of individuals, Supplementary Figure 1].

The observed number of species per plot was also higher in várzea than in terra firme forests (Kruskal-Wallis, $H=15.26$, $p<0.001$; Figure 2B), with a median number of 9 species per plot in várzea forests $(\mathrm{Q} 1=9 ; \mathrm{Q} 3=14)$ and $6(\mathrm{Q} 1=5$; $\mathrm{Q} 3=7$ ) species per plot in terra firme forests. However, when the species richness estimate was standardized by sample size and coverage, várzea and terra firme forests showed similar species-richness estimates (Figure 3). Terra firme assemblages had a lower estimated sampling completeness (84\%) than várzea (94\%; Supplementary Figure 3), despite the larger survey effort (21 surveyed plots in terra firme against 15 in várzea). Even with terra firme having a lower sampling completeness, the rarefaction and extrapolation of species-richness to the same number of individuals or coverage as the várzea samples showed similar curves (Figure 3), indicating that they have similar overall richness.

The NMDS ordination of plots along the two axes explained $53 \%$ of the variation in differences in species composition, whereas the NMDS with a single axis explained $33 \%$. The PCA ordination of plots along the first two axes explained $66 \%$ of the variation in the environmental features of plots and the first axis (PCA 1) captured the environmental differences between várzea and terra firme plots (Supplementary Figure 4). Negative values of the first PCA axis were associated with várzea plots, whereas positive values were associated with terra firme plots (Supplementary Figure 4). Várzea plots had lower terrain elevation, were vertically nearer to drainage, subjected to flooding during the high-water season, and also had lower percentage tree cover and lower canopy height than terra firme plots (Supplementary Figure 4).

There was a marked difference between butterfly composition of várzea and terra firme forests (PERMANOVA, $F=7.82$, $p<0.001$ ), captured mainly by the first axis (Figure 4A) due to the strong turnover of species composition between forest types (Figure 4B). The exclusion of rare species (singletons and doubletons) did not change the pattern found (Supplementary Figure 5). The change in species composition was associated with forest types $(t=-4.59 ; p<0.001)$, but with little evidence for effects of environmental gradients within each forest type (várzea: $t=0.09 ; p=0.93$; terra firme: $t=-0.07 ; p=0.94$; Figure $4 \mathrm{C}$ ), after controlling for spatial effects of latitude and longitude. 

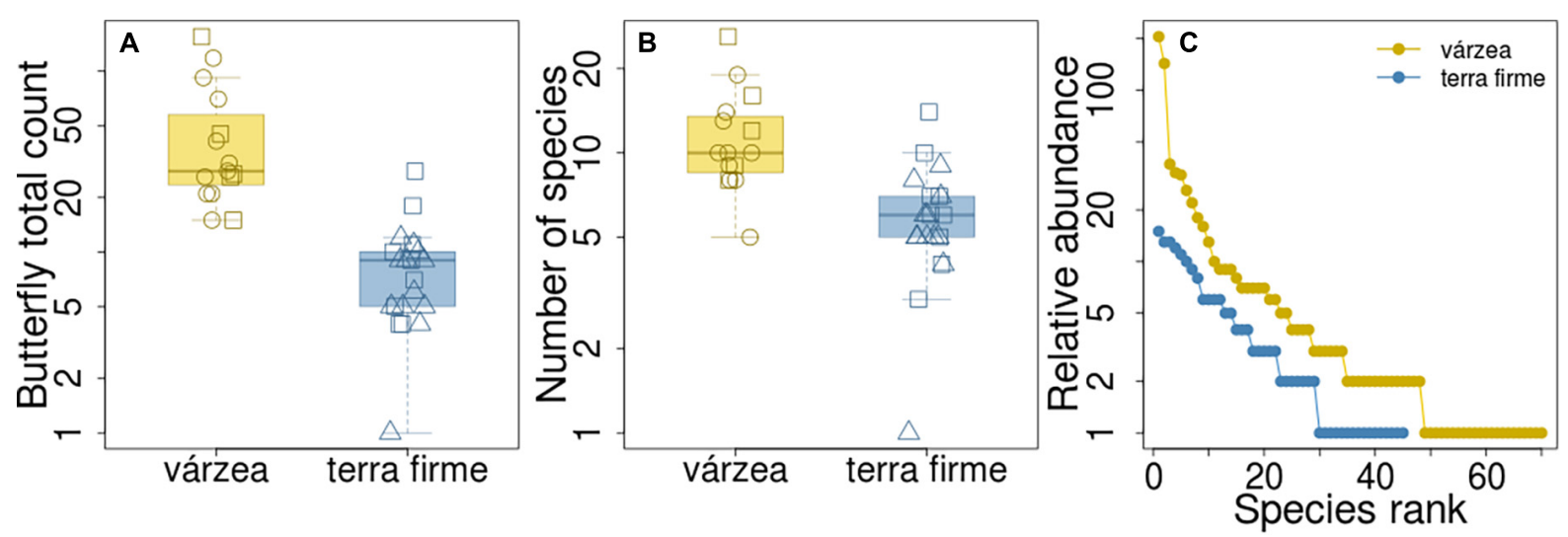

FIGURE 2 | Butterfly counts and number of species in várzea and terra firme forest plots. Difference in butterfly counts (A) and number of species (B) per plot between the two forest types. Square, circle and triangle symbols represent plots in Baixo Juruá, Mamirauá and Amanã reserves, respectively. (C) Assemblage rank-abundance distribution from the two forest types.
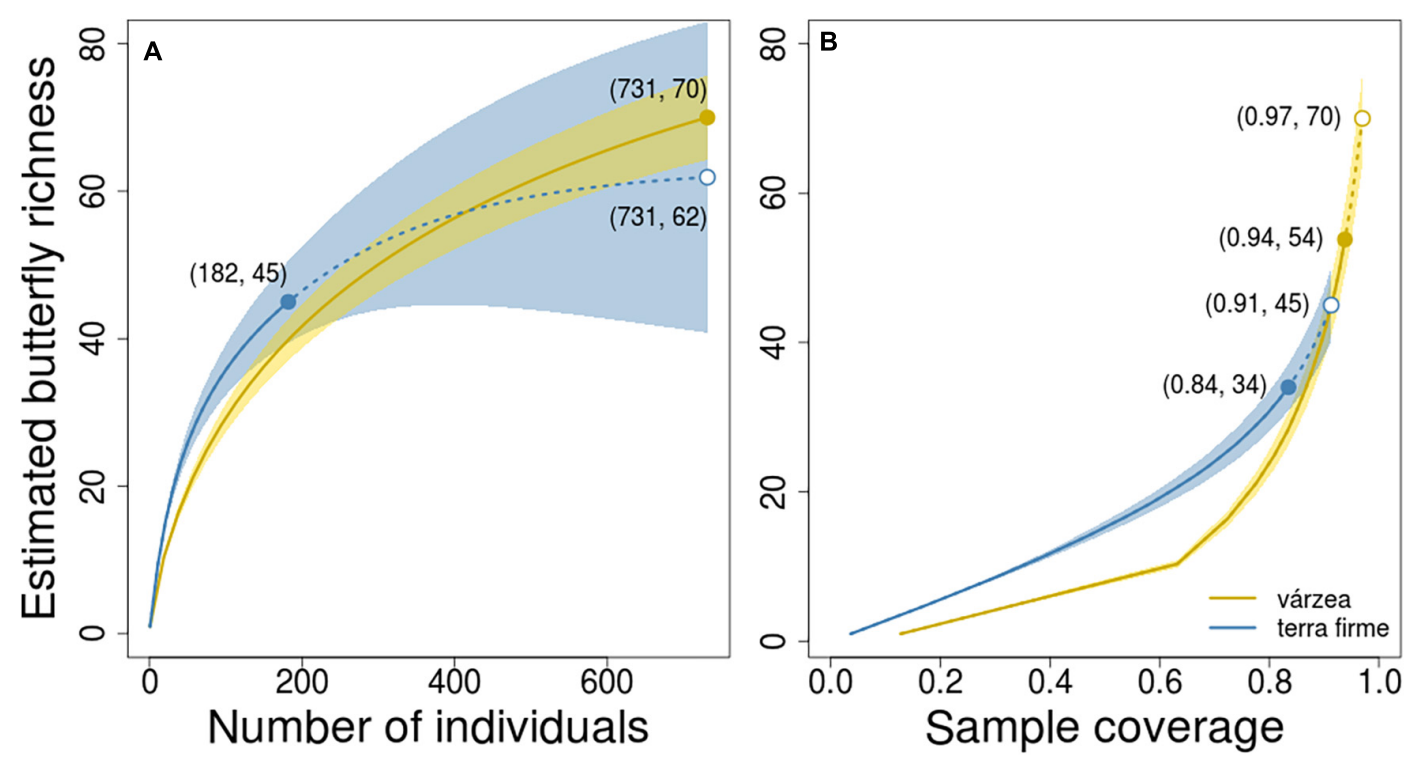

FIGURE 3 | Butterfly richness estimated by rarefaction (solid curves) and extrapolation (dashed curves) based on sample size (A) and completeness, (B) with corresponding 95\% confidence intervals (shaded areas). Solid circles indicate the observed species richness and open circles indicate the extrapolated richness in terra firme assemblages based on number of individuals (A) or sample coverage. (B) Numbers within parentheses indicate the coordinates in both graphs. Although estimated richness in várzea seems to be higher than terra firme at its maximum sample size (731 individuals in "A") or completeness (0.97 of coverage in "B"), the confidence intervals overlap and indicate the there is no statistically significant difference in richness between the two forest types.

There was no spatial autocorrelation in model residuals (Moran's I: obs.: -0.01 ; exp.: $-0.03 ; p=0.60)$, even without including latitude and longitude among predictors (Moran's I: obs.: -0.07 ; exp.: $-0.03 ; p=0.13)$.

\section{DISCUSSION}

\section{Bottom-Up Effects on Species Abundance and Richness}

We found higher butterfly total abundance in várzea than in terra firme forests, which is the same pattern reported in studies of bats (Pereira et al., 2009) and primates (Haugaasen and Peres, 2005b). The higher abundance of herbivorous, frugivorous and nectarivorous species (such as butterflies, primates and frugivorous bats) in várzea is probably due to the higher availability of food resources for these species in these forests. Seasonal flooding by white-water rivers provides an extra input of nutrients in várzea soils, which increases forest primary productivity (Irion et al., 2010). Bobrowiec et al. (2014) found that the abundance of frugivorous bats in várzea forests is even higher during the high-water season. However, for Amazonian fruit-feeding butterflies, adults tend to be more abundant during the early and mid-dry seasons, and less abundant during the wet 


\section{A}

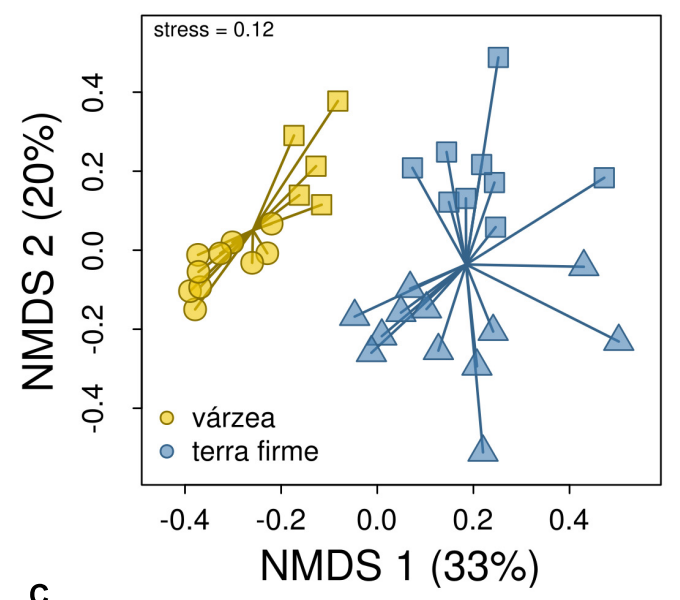

C

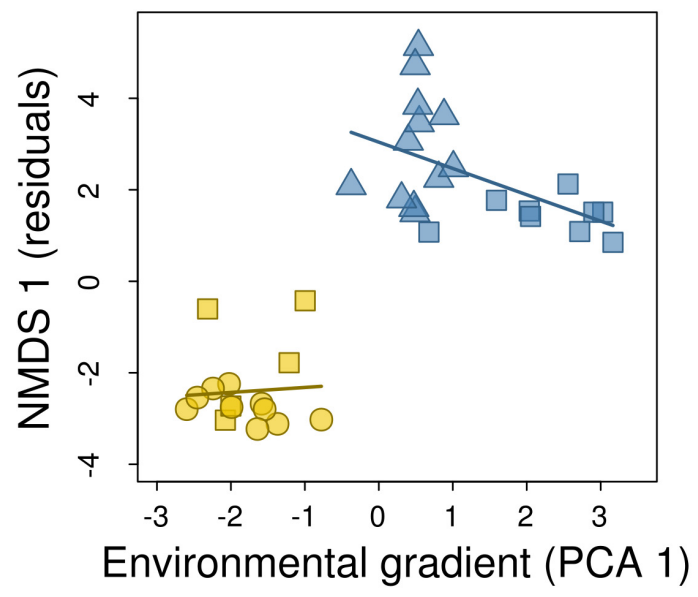

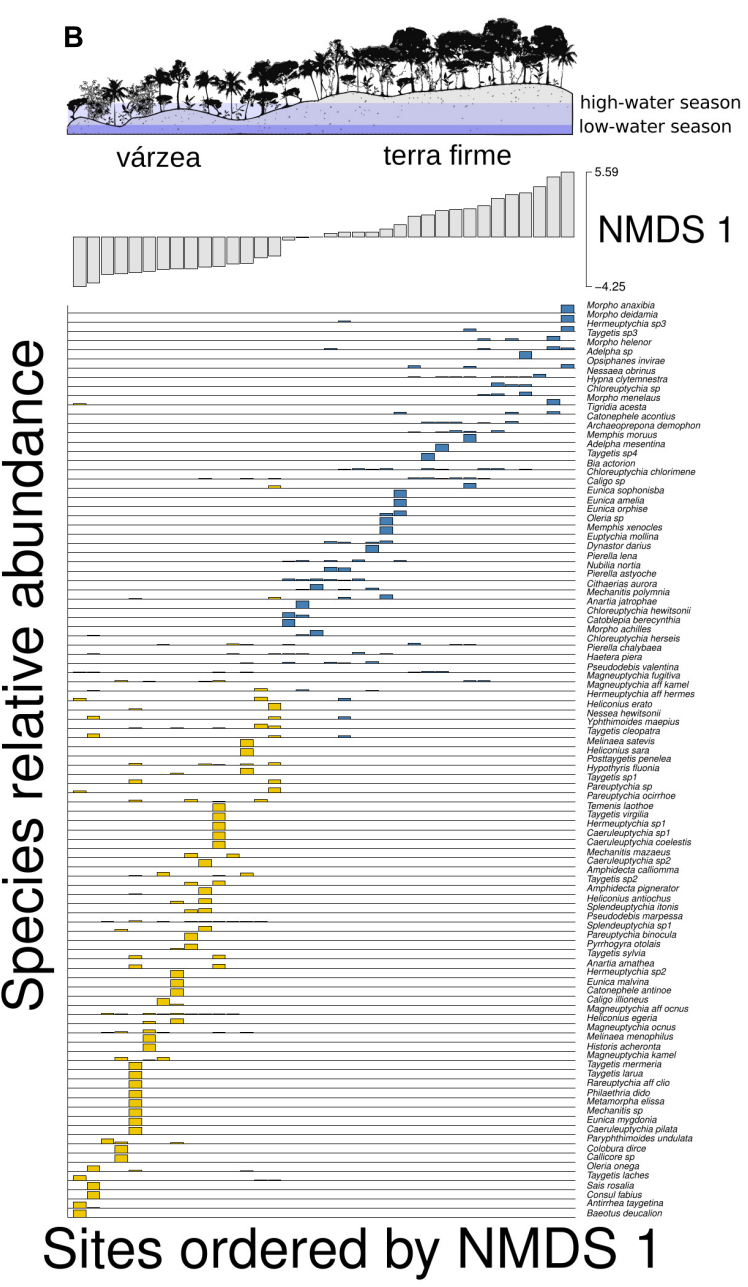

FIGURE 4 | Changes in species composition between várzea and terra firme forests. (A) Butterfly species composition in a bi-plot with the two axes derived from a NMDS ordination. Each point in the graph represents a plot located in várzea or terra firme forest and the distance between points represents the similarity of plots in terms of their species composition. Square, circle, and triangle symbols represent plots in Baixo Juruá, Mamirauá, and Amanã reserves, respectively. (B) Distribution of butterflies across sample sites. Sample sites are ordered by a single NMDS axis and bar heights show the relative abundance of butterfly species across várzea (gray) and terra firme (black) plots. (C) Change in species composition (NMDS 1) with environmental gradients (PCA 1) along and within each forest type, after controlling for the effects of latitude and longitude.

season (Barlow et al., 2007), when they probably occur in other life stages, such as herbivorous caterpillars.

We found that várzea forests also had higher species density (i.e., higher numbers of species per plot) than terra firme. This apparent difference in the number of butterfly species between the two forest types occurred because we sampled a much higher number of individuals per plot in várzea forest. When extrapolating the terra firme species richness to the same number of individuals/coverage as the várzea sample, the assemblages showed similar overall richness, even though terra firme covers a larger area, has more stratified forest structure and is much older than várzea forests. A similar species richness between flooded and unflooded forests was also found for arboreal ants (Pringle et al., 2019). Empirical experiments with arboreal arthropods demonstrated that bottom-up mechanisms in which long-term higher input of nutrients increases species density, but slightly decreases the richness of detritivores and herbivores due to increased dominance of common species (Haddad et al., 2000; Gruner and Taylor, 2006). This bottom-up process may explain why we found a higher species density, but not necessarily richness in várzea forests.

Previous studies have consistently found poorer assemblages in várzea forests for several animal groups (Haugaasen and Peres, 2005b; Bobrowiec et al., 2014; Alvarenga et al., 2018), including a recent study with butterflies (Oliveira et al., 2021). However, most of these studies reported only the species density (i.e., number of species per sampling unit) as a diversity index, and few attempted to estimate species richness by standardizing the number of species by sample size/coverage prior to undertaking such comparisons (but see Pereira et al., 2009; Oliveira et al., 2021). Therefore, the generalization of this pattern was likely based on species density (i.e., number of species per unit habitat), 
which is different from rarefied (or expected) species richness at constant total abundance (Gotelli and Colwell, 2001).

However, Oliveira et al. (2021) did estimate butterfly species richness as we did, but found higher species richness in terra firme forests than in várzea. Although our sampling design is different from theirs, which hampers comparisons between studies, there are possible reasons for this difference. One is that they sampled not only Nymphalidae species, but also five other families of butterflies, which increases the overall diversity evaluated. Also, as these authors acknowledge, their limited sample size may have affected their species-accumulation curves, which did not approach an asymptote, so comparisons between curves may have been compromised.

\section{Environmental Filters and Adaptive Species Traits}

Butterfly species composition changed with environmental gradients between forest types, but no effect of environmental gradients was detected within each forest type. It is likely that we did not detect the effects of environmental gradients within forest types because our measures of environmental variables were retrieved from GIS databases. Therefore, we caution that measuring micro-habitat characteristics in the field may be more appropriate to evaluate how assemblage structure responds to environmental gradients within each forest type.

On the other hand, species composition changed between várzea and terra firme forests. According to our PCA ordination, várzea forests are located at lower elevations nearer rivers, which causes inundation during the high-water season, and have lower tree cover and canopy height, whereas terra firme has a more complex forest structure and does not flood. The differences in butterfly species composition is probably mainly attributable to flooding, which is a direct barrier to the persistence of all grounddwelling and understorey species during the high-water season (Haugaasen and Peres, 2005a), and even for flying species (birds, Beja et al., 2010; bats, Bobrowiec et al., 2014), such as butterflies.

We also found that terra firme assemblages from different protected areas had distinct butterfly composition (see separation of symbols captured by NMDS 2 in Figure 4A). We do not believe that these differences are due to an effect of the spatial distance between these assemblages, since we have controlled for potential effects of geographical distance and did not find spatial autocorrelation. While terra firme plots from Baixo Juruá Reserve are located in a region with very old soils from Tertiary sandstones, plots from Amanã Reserve are located on more recent soils from Late-Pleistocene, or paleo-várzea forests, as they have been called (Irion et al., 2010). Even so, paleo-várzeas are more similar to terra firme than to várzea in terms of topography and vegetation structure (taller and more stratified forests). As shown by the PCA ordination, these upland plots have distinct environmental conditions, depending on the geological formation in which they are located. Therefore, we believe that the distinct butterfly compositions among terra firme plots are probably due such environmental differences among study sites.

Habitat conditions may select for the evolution of adaptive traits and behavior, which in turn may affect the ability of species to disperse to and persist at local sites. For example, the evener rank-abundance distribution in terra firme forests had a considerable contribution from Haeterini butterflies, which tended to be more abundant in this forest type. Haeterini butterflies are low-flying ground-dwelling species that feed mainly on rotting fruits and other decaying material on the forest floor (Alexander and DeVries, 2012), and adults can be abundant throughout the year (Devries et al., 2012). Wing morphology in Haeterini butterflies has evolved as a response to their habitatspecific flight behavior, i.e., gliding in-ground along the forest floor (Cespedes et al., 2015). Therefore, it is possible that the adaptive wing shape traits of these species play an important role in constraining their dispersal through flooded forests.

Similarly, adaptive behavior may help to explain the larger abundance and richness of Ithomiini species in várzea forests. Ithomines commonly form large aggregations, also known as ithomine "pockets" (DeVries, 1987). This gregarious behavior normally occurs during the dry season, when temperatures are higher and air humidity is lower, so the pockets are located in shady forest sites close to water courses (Pinheiro et al., 2008). This adaptive behavior as a response to cope with adverse climate conditions was suggested to be the main factor explaining the formation of the pockets, rather than the occurrence of large concentrations of adult food resources (Pinheiro et al., 2008). Therefore, since most of the ithomine individuals were found in a few várzea plots located near the river banks $(\sim 70 \mathrm{~m})$ and very close to small streams, it is likely that the higher abundance of ithomines in várzea forests is an adaptation of these butterflies to seek suitable local climatic conditions.

\section{The Role of Biotic Filters}

The differences in species composition between the two forest types may also be explained by species interactions, especially with their host plants. For instance, the most frequently captured species in várzea assemblages were Magneuptychia aff. ocnus, Pseudodebis marpessa, and P. valentina. Larvae of Magneuptychia species feed mainly on grasses (Beccaloni et al., 2008), which have high growth rates and rapidly occupy available substratum during the low-water season in várzea forests (Silva et al., 2013). Pseudodebis species feed on the bamboo Guadua angustifolia (Murray, 2001), which was highly abundant in the várzea plots where we surveyed most Pseudodebis butterflies (Rabelo, person. obs.). On the other hand, Bia actorion and Euptychia molina were the most frequently captured species in the terra firme assemblages. Bia actorion feeds mainly on Geonoma palms (Freitas et al., 2002), which are considered terra firme specialists and rarely occur in várzea forests (Muscarella et al., 2019). Similarly, Euptychia butterflies are known for their strong relationship with their host plants, Selaginellaceae and Neckeraceae (DeVries, 1985; Hamm and Fordyce, 2016), which are often obligate terrestrial (Selaginella) and do not occur in floodplain forests (Poulsen and Balslev, 1991; Junk and Piedade, 1993). As most tropical caterpillars are host specialists and floristic diversity is closely associated with butterfly richness (Morais et al., 2011) and composition (Graça et al., 2015), the distribution of host plants is the primary biotic limitation affecting butterfly composition at local scales. 
Another interesting example of how biotic interactions may explain our results can be seen in the Onega clearwing (Oleria onega). This species was the fourth most common species in várzea forests. Oleria are Ithomiini butterflies that are known to feed on alkaloid-rich host plants, which make the adults unpalatable to predators and all species are engaged in mimicry (Brown, 1987; Beccaloni, 1997). Although adults are unpalatable, it has been suggested that their eggs may be subject to predation or removed from leaves by Ectatomma ants, which are often found in Solanum species (Gallusser, 2002). As Ectatomma ants are weak swimmers (Yanoviak and Frederick, 2014) and do not normally occur in Amazonian seasonally flooded forests (Wilson, 1987), we hypothesize that their absence may favor the high abundance of Oleria in várzea forests.

\section{CONCLUSION}

We found that both várzea and terra firme forests have similar species richness, although the former forest type had higher species density likely due to its higher primary productivity. We also found a pronounced difference in butterfly species composition between várzea and terra firme forests. The strong turnover of butterfly species was associated with environmental differences between várzea and terra firme, but not with the environmental change within each forest type. Environmental conditions may select for the evolution of adaptive traits and behavior, which in turn may affect the ability of species to disperse to and persist at local sites. Therefore, our findings reinforce flooding as a primary environmental filter in Amazonian floodplain forests, which strongly determines the composition of butterfly assemblages, as well as the distribution of their interacting biota. The results of this study suggest that environmental and biotic filters override the effects of vegetation stratification and effects of source area on differences in the composition of butterfly assemblages in flooded and unflooded Amazonian sites at local scales.

\section{DATA AVAILABILITY STATEMENT}

The datasets generated for this study can be found in the KNB Ecoinformatics repository (https://knb.ecoinformatics.org/view/ doi:10.5063/B27SQT).

\section{ETHICS STATEMENT}

The study and collection of butterfly specimens was reviewed and approved by the Sistema de Autorização e Informação

\section{REFERENCES}

Alexander, L. G., and DeVries, P. J. (2012). Variation in capture height and trap persistence among three Costa Rican understorey butterfly species. J. Trop. Ecol. 28, 585-589. doi: 10.1017/S0266467412000533

Alvarenga, G. C., Ramalho, E. E., Baccaro, F. B., Rocha, D. G., FerreiraFerreira, J., and Dineli Bobrowiec, P. E. (2018). Spatial patterns of medium em Biodiversidade (SISBIO), Instituto Chico Mendes de Conservação da Biodiversidade (ICMBio; permission \#57444).

\section{AUTHOR CONTRIBUTIONS}

RR conceived and designed the study, collected and analyzed the data, and prepared the first draft of the manuscript. GP contributed to the study design, collected the data, and contributed to the manuscript preparation. JV contributed to the idea conception, study design, and manuscript preparation. WM contributed to study design, data analyses, and the manuscript preparation. All authors contributed to the article preparation and approved the submitted version.

\section{FUNDING}

This research was funded by the Instituto de Desenvolvimento Sustentável Mamirauá (IDSM-OS/MCTI), by the Gordon and Betty Moore Foundation, and by the Departamento de Mudanças Climáticas e Unidades de Conservação (DEMUC). This work was partly funded by the Coordenação de Aperfeiçoamento de Pessoal de Nível Superior - Brazil (CAPES) - PROEX (\#0742/2020) and by the Fundação de Amparo à Pesquisa do Estado do Amazonas (FAPEAM-PAPAC \#005/2019). RR received a Doctoral fellowship from National Council for Scientific and Technological Development (CNPq, \#142352/2017-9). WM thanks CNPq for a research fellowship (\#301873/2016-0).

\section{ACKNOWLEDGMENTS}

We thank the logistical support from Mamirauá Institute and from the Instituto Chico Mendes de Conservação da Biodiversidade (ICMBio). We thank the Departamento de Mudanças Climáticas e Unidades de Conservação (DEMUC) for providing butterfly-sampling equipment. We thank Thamara Zacca for help in species identification. The Program for Biodiversity Research (PPBio) and the National Institute for Amazonian Biodiversity (CENBAM) provided support during analyses and data storage.

\section{SUPPLEMENTARY MATERIAL}

The Supplementary Material for this article can be found online at: https://www.frontiersin.org/articles/10.3389/fevo.2021. 693178/full\#supplementary-material

and large size mammal assemblages in várzea and terra firme forests, Central Amazonia, Brazil. PLoS One 13:e0198120. doi: 10.1371/journal.pone.0 198120

Barlow, J., Overal, W. L., Araujo, I. S., Gardner, T. A., and Peres, C. A. (2007). The value of primary, secondary and plantation forests for fruit-feeding butterflies in the Brazilian Amazon. J. Appl. Ecol. 44, 1001-1012. doi: 10.1111/j.1365-2664. 2007.01347.x 
Beccaloni, G. W. (1997). Ecology, natural history and behaviour of Ithomiine butterflies and their mimics in Ecuador (LEPIDOPTERA: Nymphalidae: Ithomiinae). Trop. Lepid. 8, 103-124.

Beccaloni, G. W., Viloria, ÁL., Hall, S. K., and Robinson, G. S. (2008). Catalogue of the Hostplants of the Neotropical Butterflies. Catálogo de las Plantas Huésped de las Mariposas Neotropicales. Zaragoza: Sociedad Entomológica Aragonesa/Natural History Museum/Instituto Venezolano de Investigaciones.

Beja, P., Santos, C. D., Santana, J., Pereira, M. J., Marques, J. T., Queiroz, H. L., et al. (2010). Seasonal patterns of spatial variation in understory bird assemblages across a mosaic of flooded and unflooded Amazonian forests. Biodivers. Conserv. 19, 129-152. doi: 10.1007/s10531-009-9711-6

Bobrowiec, P. E. D., Rosa, L., do, S., Gazarini, J., and Haugaasen, T. (2014). Phyllostomid bat assemblage structure in amazonian flooded and unflooded forests. Biotropica 46, 312-321. doi: 10.1111/btp.12102

Brown, K. S. Jr. (1987). Chemistry at the Solanaceae/Ithomiinae Interface. Ann. Missouri Bot. Gard. 74, 359-397. doi: 10.2307/2399406

Cespedes, A., Penz, C. M., and DeVries, P. J. (2015). Cruising the rain forest floor: butterfly wing shape evolution and gliding in ground effect. J. Anim. Ecol. 84, 808-816. doi: 10.1111/1365-2656.12325

Chao, A., Gotelli, N. J., Hsieh, T. C., Sander, E. L., Ma, K. H., Colwell, R. K., et al. (2014). Rarefaction and extrapolation with Hill numbers: a framework for sampling and estimation in species diversity studies. Ecol. Monogr. 84, 45-67. doi: $10.1890 / 13-0133.1$

Chao, A., and Jost, L. (2012). Coverage-based rarefaction and extrapolation: standardizing samples by completeness rather than size. Ecology 93, 2533-2547. doi: 10.1890/11-1952.1

Chowdhury, S., Zalucki, M. P., Amano, T., Woodworth, B. K., Venegas-Li, R., and Fuller, R. A. (2021). Seasonal spatial dynamics of butterfly migration. Ecol. Lett. 24, 1814-1823. doi: 10.1111/ele.13787

Derraik, J. G., Closs, G. P., Dickinson, K. J., Sirvid, P., Barratt, B. I., and Patrick, B. H. (2002). Arthropod morphospecies versus taxonomic species: a case study with Araneae, Coleoptera, and Lepidoptera. Conserv. Biol. 16, 1015-1023. doi: 10.1046/j.1523-1739.2002.00358.x

DeVries, P. J. (1985). Hostplants records and natural history notes on Costa Rican Butterflies (Papilionidae, Pieridae \& Nymphlidae). J. Res. Lepid. 24, 290-333.

DeVries, P. J. (1987). The butterflies of Costa Rica and their Natural History Papilionidae, Pieridae, Nymphalidae, Vol. I. New Jersey NJ: Princeton University Press.

Devries, P. J., Alexander, L. G., Chacon, I. A., and Fordyce, J. A. (2012). Similarity and difference among rainforest fruit-feeding butterfly communities in Central and South America. J. Anim. Ecol. 81, 472-482. doi: 10.1111/j.1365-2656.2011. 01922.x

Diamond, S. E., Frame, A. M., Martin, R. A., and Buckley, L. B. (2011). Species' traits predict phenological responses to climate change in butterflies. Ecology 92, 1005-1012. doi: 10.1890/10-1594.1

Freitas, A. V., Leal, I. R., Uehara-Prado, M., and Iannuzzi, L. (2006). "Insetos como indicadores de conservação da paisagem," in Biologia da Conservação e Manejo da Vida Silvestre, eds L. Cullen Jr., R. Rudran, and C. Valladares-Padua (Curitiba: Editora da Universidade Federal do Paraná), 357-384.

Freitas, A. V. L., Iserhard, C. A., Santos, J. P., Carreira, J. Y. O., Ribeiro, D. B., Melo, D. H. A., et al. (2014). Studies with butterfly bait traps: an overview. Rev. Colomb. Entomol. 40, 203-212.

Freitas, A. V. L., Murray, D., and Brown, J. S. (2002). Immatures, natural history and the systematic position of Bia actorion (Nymphalide). J. Lepid. Soc. 56, $117-122$.

Gallusser, S. A. (2002). Biology, Behaviour and Taxonomy of Two Oleria Onega Subspecies (Ithomiinae, Nymphalidae, Lepidoptera) in North-Eastern Peru. Doctoral's Thesis. Neuchâtel: University of Neuchâtel.

Gascon, C. (1996). Amphibian litter fauna and river barriers in flooded and nonflooded Amazonian rain forest. Biotropica 28, 136-140. doi: 10.2307/2388779

Gotelli, N. J., and Colwell, R. K. (2001). Quantifying biodiversity: procedures and pitfalls in the measurement and comparison of species richness. Ecol. Lett. 4, 379-391. doi: 10.1046/j.1461-0248.2001. 00230.x

Graça, M. B., Morais, J. W., Franklin, E., Pequeno, P. A. C. L., Souza, J. L. P., and Bueno, A. S. (2015). Combining taxonomic and functional approaches to unravel the spatial distribution of an amazonian butterfly community. Environ. Entomoly 45, 301-309. doi: 10.1093/ee/nvv183
Graça, M. B., Pequeno, P. A. C. L., Franklin, E., Souza, J. L. P., and Morais, J. W. (2017a). Taxonomic, functional, and phylogenetic perspectives on butterfly spatial assembly in northern Amazonia. Ecol. Entomol. 42, 816-826. doi: 10. 1111/een.12454

Graça, M. B., Souza, J. L. P., Franklin, E., Morais, J. W., and Pequeno, P. A. C. L. (2017b). Sampling effort and common species: Optimizing surveys of understorey fruit-feeding butterflies in the Central Amazon. Ecol. Indic. 73, 181-188. doi: 10.1016/j.ecolind.2016.09.040

Gruner, D. S., and Taylor, A. D. (2006). Richness and species composition of arboreal arthropods affected by nutrients and predators: a press experiment. Oecologia 147, 714-724. doi: 10.1007/s00442-005-0337-4

Haddad, N. M., Haarstad, J., and Tilman, D. (2000). The effects of long-term nitrogen loading on grassland insect communities. Oecologia 124, 73-84. doi: $10.1007 / \mathrm{s} 004420050026$

Hamm, C. A., and Fordyce, J. A. (2016). Selaginella and the satyr: euptychia westwoodi (Lepidoptera: Nymphalidae) oviposition preference and larval performance. J. Insect Sci. 16, 1-4. doi: 10.1093/jisesa/iew018

Haugaasen, T., and Peres, C. A. (2005a). Mammal assemblage structure in Amazonian flooded and unflooded forests. J. Trop. Ecol. 21, 133-145. doi: 10.1017/S026646740400207X

Haugaasen, T., and Peres, C. A. (2005b). Primate assemblage structure in Amazonian flooded and unflooded forests. Am. J. Primatol. 67, 243-258. doi: 10.1007/s10329-009-0135-4

Haugaasen, T., and Peres, C. A. (2006). Floristic, edaphic and structural characteristics of flooded and unflooded forests in the lower Rio Purús region of central Amazonia. Brazil. Acta Amaz. 36, 25-36. doi: 10.1590/s004459672006000100005

Hortal, J., de Bello, F., Diniz-Filho, J. A. F., Lewinsohn, T. M., Lobo, J. M., and Ladle, R. J. (2015). Seven shortfalls that beset large-scale knowledge of biodiversity. Annu. Rev. Ecol. Evol. Syst. 46, 523-549. doi: 10.1146/annurevecolsys-112414-054400

Hsieh, T. C., Ma, K. H., and Chao, A. (2016). iNEXT: an R package for rarefaction and extrapolation of species diversity (Hill numbers). Methods Ecol. Evol. 7, 1451-1456. doi: 10.1111/2041-210X.12613

Hubbell, S. P. (2005). Neutral theory in community ecology and the hypothesis of functional equivalence. Funct. Ecol. 19, 166-172. doi: 10.1111/j.0269-8463. 2005.00965. $\mathrm{x}$

Huete, A., Didan, K., Miura, T., Rodriguez, E. P., Gao, X., and Ferreira, L. G. (2002). Overview of the radiometric and biophysical performance of the MODIS vegetation indices. Remote Sens. Environ. 83, 195-213. doi: 10.1016/S00344257(02)00096-2

ICMBio (2009). Plano de Manejo - Reserva Extrativista do Baixo Juruá. Tefe, AM: Instituto Chico Mendes de Conservação da Biodiversidade - ICMBio / Ministério do Meio Ambiente.

IDSM (2010). Plano de Gestão Reserva de Desenvolvimento Sustentável Mamirauá RDSM. Tefé: MCTI/IDSM-OS.

Irion, G., Mello, J. A. S. N., Morais, J., Piedade, M. T. F., Junk, W. J., and Garming, L. (2010). "Development of the amazon valley during the middle to late quaternary: sedimentological and climatological observations," in Amazonian Floodplain Forests: Ecophysiology, Biodiversity and Sustainable Management, eds W. J. Junk, M. T. F. Piedade, F. Wittmann, J. Schöngart, and P. Parolin (New York NY: Springer), 27-42. doi: 10.1007/978-90-481-8725-6_2

Junk, W. J., and Piedade, M. T. F. (1993). Herbaceous plants of the Amazon floodplain near Manaus: species diversity and adaptations to the flood pulse. Amazoniana 7, 467-484.

Junk, W. J., Piedade, M. T. F., Schöngart, J., and Wittmann, F. (2012). A classification of major natural habitats of Amazonian white-water river floodplains. Wetl. Ecol. Manag. 20, 461-475. doi: 10.1007/s11273-012-9268-0

Legendre, P., and Legendre, L. (1998). Numerical Ecology. Amsterdam: Elsevier.

MacArthur, R. H. (1969). Patterns of communities in the tropics. Biol. J. Linn. Soc. 1, 19-30. doi: 10.1111/j.1095-8312.1969.tb01809.x

MacArthur, R. H., and MacArthur, J. W. (1961). On bird species diversity. Ecology $42,594-598$.

MacArthur, R. H., and Wilson, E. O. (1967). The Theory of Island Biogeography. Princeton NJ: Princeton University Press.

Magnusson, W. E., Lima, A. P., Luizão, R., Luizão, F., Costa, F. R. C., Castilho, C. V., et al. (2005). RAPELD: a modification of the Gentry method for biodiversity surveys in long-term ecological research sites. Biota Neotrop. 5, 21-26. 
Melack, J. M., and Hess, L. L. (2010). "Remote sensing of the distribution and extent of wetlands in the Amazon basin," in Amazonian Floodplain Forests: Ecophysiology, Biodiversity and Sustainable Development, eds W. J. Junk, M. T. F. Piedade, F. Wittmann, J. Schöngart, and P. Parolin (New York NY: Springer), 43-59. doi: 10.1007/978-90-481-8725-6_3

Morais, H. C., Sujii, E. R., Almeida-Neto, M., De Carvalho, P. S., Hay, J. D., and Diniz, I. R. (2011). Host plant specialization and species turnover of caterpillars among hosts in the Brazilian Cerrado. Biotropica 43, 467-472. doi: 10.1111/j. 1744-7429.2010.00736.x

Murray, D. L. (2001). Systematics of Neotropical Satyrine Butterflies (Nymphalidae: Satyrinae: Euptychiina) Based on Larval Morphology and DNA Sequence Data and the Evolution of Life History Traits. Doctoral's Dissertation. Baton Rouge (LA): Louisiana State University.

Muscarella, R., Bacon, C. D., Faurby, S., Antonelli, A., Kristiansen, S. M., Svenning, J. C., et al. (2019). Soil fertility and flood regime are correlated with phylogenetic structure of Amazonian palm communities. Ann. Bot. 123, 641-655. doi: 10. 1093/aob/mcy196

Oksanen, A. J., Blanchet, F. G., Kindt, R., Legendre, P., Minchin, P. R., Hara, R. B. O., et al. (2013). vegan: Community Ecology Package. $R$ package version 2.0-10.

Oliveira, I. F., Baccaro, F. B., Werneck, F. P., Zacca, T., and Haugaasen, T. (2021). Marked differences in butterfly assemblage composition between forest types in Central Amazonia. Brazil. Forests 12:942. doi: 10.3390/f12070942

Pereira, M. J. R., Marques, J. T., Santana, J., Santos, C. D., Valsecchi, J., Queiroz, H. L., et al. (2009). Structuring of Amazonian bat assemblages: the roles of flooding patterns and floodwater nutrient load. J. Anim. Ecol. 78, 1163-1171. doi: $10.1111 / j .1365-2656.2009 .01591 . x$

Pinheiro, C. E. G., Medri, I. M., and Salcedo, A. K. M. (2008). Why do the ithomiines (Lepidoptera, Nymphalidae) aggregate? Notes on a butterfly pocket in central Brazil. Rev. Bras. Entomol. 52, 610-614. doi: 10.1590/s008556262008000400012

Poulsen, A. D., and Balslev, H. (1991). Abundance and cover of ground herbs in an Amazonian rain forest. J. Veg. Sci. 2, 315-322. doi: 10.2307/3235922

Pringle, E. G., Santos, T. F. D., Gonçalves, M. S., Hawes, J. E., Peres, C. A., and Baccaro, F. B. (2019). Arboreal ant abundance tracks primary productivity in an Amazonian whitewater river system. Ecosphere 10:e02902.

R Development Core Team (2018). R: A Language and Environment for Statistical Computing. Vienna: R Foundation for Statistical Computing.
Ribeiro, D. B., and Freitas, A. V. L. (2012). The effect of reduced-impact logging on fruit-feeding butterflies in Central Amazon. Brazil. J. Insect Conserv. 16, 733-744. doi: 10.1007/s10841-012-9458-3

Ruokolainen, K., Moulatlet, G. M., Zuquim, G., Hoorn, C., and Tuomisto, H. (2018). river network rearrangements in amazonia shake biogeography and civil security. Preprints 1-16. doi: 10.20944/preprints201809.0 168.v1

Santos, E. C., Mielke, O. H. H., and Casagrande, M. M. (2008). Butterfly inventories in Brazil: the state of the art and the priority-areas model for research aiming at conservation. Nat. Conserv. 6, 178-200.

Silva, T. S. F., Melack, J. M., and Novo, E. M. L. M. (2013). Responses of aquatic macrophyte cover and productivity to flooding variability on the Amazon floodplain. Glob. Chang. Biol. 19, 3379-3389. doi: 10.1111/gcb.12308

Wilson, E. O. (1987). The arboreal ant fauna of peruvian amazon forests: a first assessment. Biotropica 19, 245-251. doi: 10.2307/2388342

Wittmann, F., Junk, W. J., and Piedade, M. T. F. (2004). The várzea forests in Amazonia: flooding and the highly dynamic geomorphology interact with natural forest succession. For. Ecol. Manage. 196, 199-212. doi: 10.1016/j.foreco. 2004.02.060

Yanoviak, S. P., and Frederick, D. N. (2014). Water surface locomotion in tropical canopy ants. J. Exp. Biol. 217, 2163-2170. doi: 10.1242/jeb.101600

Conflict of Interest: The authors declare that the research was conducted in the absence of any commercial or financial relationships that could be construed as a potential conflict of interest.

Publisher's Note: All claims expressed in this article are solely those of the authors and do not necessarily represent those of their affiliated organizations, or those of the publisher, the editors and the reviewers. Any product that may be evaluated in this article, or claim that may be made by its manufacturer, is not guaranteed or endorsed by the publisher.

Copyright (๑) 2021 Rabelo, Pereira, Valsecchi and Magnusson. This is an open-access article distributed under the terms of the Creative Commons Attribution License (CC BY). The use, distribution or reproduction in other forums is permitted, provided the original author(s) and the copyright owner(s) are credited and that the original publication in this journal is cited, in accordance with accepted academic practice. No use, distribution or reproduction is permitted which does not comply with these terms. 